\title{
Teaching electronic music - journeys through a changing
}

\section{landscape}

Simon Emmerson

De Montfort University | United Kingdom

\begin{abstract}
In this essay, electronic music composer Simon Emmerson examines the development of electronic music in the UK through his own experience as composer and teacher. Based on his lifetime experiences, Emmerson talks about the changing landscape of teaching electronic music composition: 'learning by doing' as a fundamental approach for a composer to find their own expressive voice; the importance of past technologies, such as analogue equipment and synthesizers; the current tendencies of what he calls the 'age of the home studio'; the awareness of sonic perception, as opposed to the danger of visual distraction; questions of terminology in electronic music and the shift to the digital domain in studios; among other things. [note by editor].
\end{abstract}

Keywords: electronic music in UK, contemporary music, teaching composition today. 


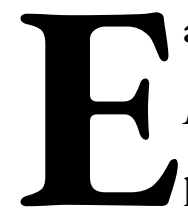

arly learning. The remark of Arnold Schoenberg (in the 1911 Preface to his Theory of Harmony) - "This book I have learned from my pupils" - is true for me, too. Teaching is learning - without my students I would not keep up nearly so well with important changes in approaches to music making, and it would be more difficult to develop new ideas and skills. Especially for music composition, teaching is about enabling individuals (and groups) to find their voice. And what their voice says is profoundly rooted in both space (place) and time (history).

'Learning by doing' is a fundamental approach. My first experience of 'being taught how to make electronic music' was during my university studies at Cambridge UK. I had arrived at Clare College, Cambridge in October 1968 to study Natural Sciences (Physics, Chemistry, Crystalline State) - I was only later to add music formally through the addition of an 'education' component of the degree. The next door Kings College had appointed two resident composer research fellows in succession - Roger Smalley (not related to Denis Smalley) and Tim Souster who together founded the live electronics group Intermodulation in 1969. The technical core of this was funded from a grant from Kings to buy EMS VCS3 synthesisers and tape recorders. By good fortune I got to know them and became first an informal then later a formal student with them both. I learnt the basics of the VCS3 rapidly and helped (as roadie) with many of their UK performances through to 1975. The group disbanded the following year. I purchased my own Synthi-AKS (a portable 'suitcase' version of the VCS3) in early 1973. Both Smalley and Souster also gave talks to clubs, societies and informal small groups - very much outside the normal music curriculum - and so I got to know a few basic works: Luc Ferrari's Presque Rien Nr.1 and Stockhausen's Hymnen, listened to from end to end without a break, are clear early memories from such presentations. Surprisingly my own college library possessed the (mono) LP of Stockhausen's Gesang der Jünglinge, and Elektronische Studien.

Intermodulation's repertoire was very eclectic - not at all ideological (Emmerson 1991). In addition to the European high modernists, the American experimental traditions were well represented, both 'postCage' and 'minimalist' branches, as was the 'English experimental' tradition of Cornelius Cardew and friends - whom Roger and Tim knew well. Cardew and Chris Hobbs visited to perform a paragraph from Cardew's The Great Learning. Around this time I also met Karlheinz Stockhausen for the first time during rehearsals with Intermodulation in Cambridge for his multi-group work Sternklang (1971). 


\section{First steps}

I started teaching a form of electronic music composition shortly after graduating from Cambridge in 1972. My degree had included an 'add on' teaching certificate in both music and physics and I was employed in a state comprehensive school in Stevenage from 1972-74. There I taught in both the music and science departments, students of a wide range of ages (11-18 years). The local education authority was supportive of new music developments including tape recording and manipulation techniques, graphic scores and improvisation. All these I tried (with varying degrees of success). We explored the standard tape techniques: speed change, reversal, using the microphone as a 'performing device' - I have always been committed to 'live electronic music' and most of these early exercises had an element of live performance. I remember an 'after school' ensemble of older pupils formed a small band which performed to the whole school assembly one morning - inside piano sounds, cymbals, tape sounds. The authority even paid for a weekend workshop for all music teachers in the area led by John Paynter, a great pioneer of progressive music education in the UK.

In addition I taught at the local 'Saturday Music Centre' - these were voluntary centres run by the local authority, traditionally for choirs, orchestras, ensembles. I was invited to run a class in the gaps between ensemble rehearsals - so for half an hour up to an hour for some of the young people - again, using basic recording and tape techniques. I was also invited around this time to set up an 'adult evening class' at what was then Hatfield Polytechnic (now the University of Hertfordshire). This class was furnished with a wider range of equipment, more tape recorders, sound sources (percussion instruments) - I would also supplement this bringing my own Synthi-AKS, using both the synthesis and processing (filters, ring modulators, enveloping) modules. These were all practical classes. The college library was supportive and purchased all the scores and recordings I requested. When we listened to the music it was with the aim of 'applying it' to our practical skills and ideas - not too 'historical' in a linear or aesthetic sense.

Improvisation and listening were the two key skills underlying the mechanical 'techniques' of the systems. Occasionally numerical systems and more commonly graphic scores might be used to generate materials - or at least to 'form' them into shapes and trajectories over time. The 1970s were a great time for progressive music making in the UK. While not specific to electronic music there was not much divide between the various branches of 'the experimental' - an openness that crossed ideological boundaries. 


\section{Designing a studio for composition and teaching}

In 1974 I joined City University London as a research student on a (two year) $\mathrm{PhD}$ 'Electronic Music Studentship' funded by the 'Worshipful Company of Musicians' (an ancient foundation). There, too, I was asked to teach in the 'adult education' department, both practical workshops and more traditional aesthetics/history classes. The foundation of the music department (proper) was in 1975 when undergraduate (Bachelors) music students arrived.

I was asked immediately to research different electroacoustic studio 'models' with visits to already established studios throughout the UK. Durham (Peter Manning) and York (Richard Orton) were immediately relevant. The resulting studio at City was designed for both research-composition and teaching. The layout of an analogue studio is fundamental to teaching and tutorial techniques - and not always compatible between solo and multiple users (a class). The core of many UK studios at this time was a bank of stereo tape recorders, a kind of 'flexible multitrack' area where (stereo) tracks could be slipped in time - providing the composer had fast and accurate dexterity to switch tapes on/off at exactly the right time!

The Revox B77s found commonly were modified to have a flat top and the electronic 'line up' controls open to view for regular use. We also created a single 'outboard' (remote) control super-panel with which you could programme each Revox: 'play', 'record' etc. then hit a single 'action!' button. This was clearly a form of performance: rehearsed with intensity - then play! It is thus true to say that automation increased accuracy but reduced the performative in the studio.

\section{Evolution - options and choices - situating the 'live'}

Studios and hence teaching techniques are a form of 'archaeology'. Something new is built, something old is lost yet the layout and functions change more slowly. A studio carries its layers of history as a tree adds rings - or perhaps as a tortoise grows its shell. In the early years there were contrasting teaching techniques available. For example there were those who gave beginner students a range of recorded sound sources without any indication of origin. This is an approach designed to encourage a Schaefferian écoute réduite (reduced listening) - sound objects for analytical reflection. I was not purist in this regard. I wanted students to understand sound and its production by feel or by touch - not simply 
through perception. If this made reduced listening more difficult it was for me a small price to pay for understanding how sound worked in the world - how it was produced, was transmitted, was received. This relates directly to my own love of live electronics. Clearly bow an instrumentalist - and I include vocalist in this word - works and produces sound is of fundamental importance. There can be no reduced listening for the truly 'live'! I later suggested that 'live' was a better term to 'real time' which I argued was an unhelpful product of the midi-computer-sequencer era (Emmerson 1994).

Sometimes live electronic music has a difficult position in teaching practice. Elements may be from 'acousmatic' traditions of sound transformation in the studio, others from more embodied 'performative' traditions of instrumental virtuosity and its extension on stage - the composer may design a 'prosthesis' of the instrumental to cross over space and time in new ways. I have written about this as the tension between the instrument 'aspiring to the condition of the acousmatic' as opposed to the electronics 'aspiring to the condition of the instrumental' (Emmerson 2007, ch.4) - these can have an uneasy relationship where the performer becomes central and must play now a more enhanced role in the whole negotiation of bringing the work to life (Emmerson 2013). Indeed since moving to De Montfort University in 2004 I have worked with performer students almost as much as with composers.

In a teaching environment no live electronic work is complete until it has been performed (preferably also recorded). Performance is an essential part of the learning process and should feedback (and if necessary modify) the score (if there is one) plus electronic patch. As an external examiner I will not examine works that are 'scores' alone.

From my own teaching experience and observing the works of my students I arrived at designations for 'space frames' that for me suggest so much more than mere 'place holders' of scale - they seem to demand content! These frames can however become the focus of technological application - they can now become an instrument of play. We can now play with spaces and their relationships. This is a prosthesis that can work both ways - we can reach out (and up) but also reach in (and down). I do not mean this simply as Newtonian space (extension) - but in a more grounded sense of the places we inhabit (Emmerson 2017, 2018).

\section{Joining up the digits}

The steady transition to digital means was slow and not always completely logical. The City 
University studio purchased one of the earliest Fairlight CMIs in the UK - an early digital sampler which did great work at the hands of a series of Latin American composers who were doing PhDs in the studio in the mid-1980s - Alejandro Viñao, Javier Alvarez, Julio d’Escriván - and others including myself (in Emmerson 2009 I discuss their unique view of pulse and rhythm contra the prevailing electroacoustic aesthetic in the UK at the time).

In the 1980s Midi developed but retained its controversial role in 'classical' electroacoustic music making - City (unlike other UK studios which retained a stronger Schaefferian tradition) had embraced the theory and practice of 'performance control languages' with the Fairlight CMI. But the advent of cheaper sampler (Akai), synthesiser (especially Yamaha's FM 'TX' series) and processor (Yamaha SPX series and Alesis) modules from the middle to later 1980s would steadily shift teaching from studio 'class' to 'workstation' cluster: students working individually with a 'walk around' tutor. Sharing work needed to be planned differently. Tape did not go away overnight with this invasion of the rack modules and personal computer control. Recording of the results had gone only partly digital with final mastering (using modified video machines). Analogue multi-track tape remained in place for some years and would only really go when computer based DAWs arrived slowly in the 1990s. But pedagogy changed gear steadily - endless boxes of tapes gave way only slowly to floppy disc storage.

Some of my colleagues elsewhere in the UK preserved their tape-based classes longer on the basis that it gave the medium a sense (a feeling) of 'physicality' - a sound object was a real object (length of tape). But I remember taking the plunge away from tape and installing a small laboratory of Apple Macs with a simple sequencer controlling an Akai sampler (no synthesis - that was added only later). As a community we have almost failed to discuss the consequences of the revolution that was visualisation, that is screen representation of sound. Put simply if the cursor is at NOW - we can see into the future, what is coming next. This is a more fundamental change than simply the ability to 'shunt' sounds around on screen. The function of memory itself shifts towards interpreting visual information. We need to be careful in our teaching to ensure that we do not privilege the visual information over what is actually heard! Against MacLuhan I have always argued we live in an increasingly 'sonic' world - but then I would say that wouldn't I? That is for another day...

I will add a final paragraph on the shift in teaching imperatives in the age of the home studio. I shall keep it simple. Firstly the standard of monitoring is rarely good in home studios (of course there are exceptions!) - I am not assuming the purist acousmatic tradition here. Nor am I assuming universities or 
other institutions are the only places where 'good monitoring' can happen. We need flexible publicly available spaces to try things out in ways impossible 'at home'. We need a range of options from the highest sonic quality through to more open spaces and places to experience sound. (I have argued for such a 'Sound House' in Emmerson (2001)). Then we need a community, sharing an interest, sharing ideas and sounds, giving sympathetic and supportive feedback (Emmerson 1989). This does not simply 'happen'. The role of teachers remains as it was almost fifty years ago when I began in this wonderful field - to encourage and enable, to nurture and share, and to continue to learn.

\section{REFERENCES}

EMMERSON, Simon. (1989), 'Composing Strategies and Pedagogy', Contemporary Music Review 3(1), pp. 133-144

. (1991), 'Live Electronic Music in Britain: three case studies', Contemporary Music Review 6(1), pp. $179-195$

. (1994), "Live' versus 'real-time”, Contemporary Music Review 10(2), pp. 95-101

. (2001), 'New spaces/new places: a Sound House for the performance of electroacoustic music and sonic art', Organised Sound 6(2), pp.103-105

. (2007), Living Electronic Music, Aldershot: Ashgate (now Routledge).

. (2009), 'Personal, local, universal - where are we?', Proceedings of the Electroacoustic Music

Studies Network Conference 2009 (EMS09), Buenos Aires. http://www.emsnetwork.org/ems09/papers/emmerson.pdf

. (2013), 'Rebalancing the discussion on interactivity', Proceedings of the Electroacoustic Music Studies Network Conference 2013 (EMS13), Lisbon. http://www.ems-network.org/spip.php?article384

. (2017), 'Performance with Technology: Extending the Instrument - From Prosthetic to Aesthetic', in The Routledge Companion to Sounding Art (Marcel Cobussen, Vincent Meelberg and Barry Truax eds.), New York: Routledge, pp.427-437.

. (2018), The Routledge Research Companion to Electronic Music: Reaching out with Technology (editor and contributor), Abingdon: Routledge

\section{ABOUT THE AUTHOR}

Simon Emmerson studied at Cambridge University and City University London. Composer and writer on electronic music since the early 1970s, he is now Professor of Music, Technology and Innovation at De Montfort University, Leicester. He founded the electroacoustic music studio at City University London in 1975 where he remained until 2004. He was founder 
Secretary of the Electro-Acoustic Music Association of Great Britain (EMAS) in 1979 as well as later Board member of Sonic Arts Network (to 2004) and Sound and Music (2008-2013). He was Edgard Varese Visiting Professor at TU, Berlin (2009-10) and Visiting Professor and Composer at the Western Australian Academy of Performing Arts (Perth) in November 2016. Recent commissions include: GRM (Paris), Inventionen (Berlin), Sond-Arte Ensemble (Lisbon), BEAST (Birmingham) and for soloists Darragh Morgan (violin), Philip Mead (piano), Carla Rees (flute) and Heather Roche (clarinet). Recordings: Sargasso. Writings include: The Language of Electroacoustic Music (1986), Living Electronic Music (2007), The Routledge Research Companion to Electronic Music (2018), coeditor Expanding the Horizon of Electroacoustic Music Analysis (CUP, 2016). Keynotes include: ACMC 2011 (Auckland), ICMC 2011 (Huddersfield), Music Science Technology 2012 (São Paulo), WOCMAT 2012 (Taiwan), Alternative Histories of Electronic Music 2016 (London). E-mail: s.emmerson@dmu.ac.uk 